\title{
Is Education for Using Humour in Nursing Needed? (Slovenian Case Study on Sociological and Ergonomic Aspects of the Impact of Humour on Nursing Professionals)
}

\author{
Jana Goriup - Jadranka Stričević - Vida Sruk ${ }^{*}$ \\ Received: June 24, 2017; received in revised form: November 6, 2017; \\ accepted: November 7, 2017
}

\begin{abstract}
:
Introduction: Although there has been considerable discussion regarding the presence of therapeutic aspects of humour in the nurse educational programme and syllabus, little is known about the use of humour in the nurse - patient relationship and the needed topics in the Slovene educational system for nurses. From educational and medical perspectives, humour is anything that evokes laughter and it has been proven that laughter contributes to physical health. A sense of humour in nursing has a conformist, quantitative and productive importance which is manifested through the essential elements of humour: meta-communication sensitivity, personal affection for humour and emotional admissibility. As nurses spend a lot of time with patients, humour adds to the quality of their work as well as to the nurses' satisfaction with their work with patients. The aim of this paper is to contribute to a better understanding of the significance of humour in nursing both for the employees and for the patients and to discuss humour within the framework of nursing profession in Slovenia. The specific objective of our study is to explore the attitudes of Slovenian nurses towards humour and their actual use of humour during their interaction with patients.

Methods: For the purpose of this study, a quantitative research methodology was adopted. A questionnaire was used to collect data on the topic and a set of statistical analyses (frequency distribution method, the $\chi^{2}$ and Spearman rank correlation test) was performed on the data obtained.

Results: Our study shows that Slovenian nurses are prone to the use of humour in their work and they welcome it as an integral part of their work with patients. We found that humour also enhances their sense of belonging to the nursing profession and serves as a tool for socialization.

Discussion: Humour, employed in nursing can help overcome certain difficulties which nurses face in the workplace as they also try to fulfil some social objectives and get socialized via humour. These psychological-sociological features of humour stand out as cognitive and social benefits of the positive emotions of joy, the use of humour for social communication and their influence on the release of stress and coping, which draws from the ergonomics of humour as social interaction. Therefore, topics of humour in nurse education are required.
\end{abstract}

\footnotetext{
* Jana Goriup, Alma Mater Europaea Maribor, Maribor, Slovenia; jana.goriup@ guest.um.si

Jadranka Stričević, University of Maribor, Faculty of Health Sciences, Maribor, Slovenia; jadranka.stricevic@um.si

Vida Sruk, University of Maribor, Faculty of Economics and Business, Maribor, Slovenia; vida.sruk@um.si
} 


\title{
Acta Educationis Generalis \\ volume 7, 2017, issue 3
}

\begin{abstract}
Limitations: 279 Slovenian nurses with different levels of education participated in the study.

Conclusions: Humour should be used by nurses since it is important in their professional interaction with patients. It can be used as a bridge between individuals and can serve as a means of individual's integration into groups, cultures and, consequently, into the society as a whole.
\end{abstract}

Key words: education, humour, nurse, nursing, patients.

\section{Introduction}

Humour is most frequently defined as the ability of a person to understand funny contents of some situation. It is explained as the (co)experiencing of happy, funny situations and events as well as human imperfections and weaknesses in an inoffensive and funny form. The most frequent communicative competences assigned to humour in everyday life are: conveying important or sensitive messages, maintaining social contacts and reducing tensions among people. Sociologists are convinced that humour functions as a socializing agent either for an individual within a group and/or for a group in the global society because it also represents social relations in the social environment in which it occurs.

As nurses spend a lot of time with patients, humour is an important factor of the quality of their work. It is either a factor which has an impact on the quality of their work or a factor which influences the relationships within a medical team. In addition, it is an important factor having an effect on the nurses' satisfaction with their work with patients.

Humour is very important for all participants in nursing. Its importance is shown in different development areas such as personal development, aesthetic development, intellectual development and, most of all, social development. Humour is almost obligatory and practically self-evident, and is usually subconsciously used by everyone in the society. It teaches us how to become integrated into the society. As such, humour is more than just a means for good communication of a nurse with a patient and a means for the socialization of the patient since it also affects the nurses' abilities, persistence, self-confidence and resourcefulness as well as their work environment and (even) their health. Doctors, psychologists, sociologists and psychiatrists have proven that laughter contributes to physical health. It releases endorphins, i.e. the hormones which reduce stress, relieve the feelings of disappointment and trigger an overall feeling of comfort. Scientists know that endorphins are a natural analgesic which inhibits pain. Researchers have also found that laughter causes the inner lining of blood vessels to expand, which increases blood flow and triggers the feelings of good physical health. Last but not least, laughter relieves the body of the stress hormone cortisol.

From medical perspective, the word humour stands for that which causes laughter. The word itself stems from Latin with its original sense being "moisture", "bodily fluid" and its secondary sense being in "good mood". The shift in the meaning of humour from a bodily fluid to merriment is based on Hippocrates' theory of medicine which states that "a person's well-being depends on the proportions of four bodily fluids, i.e. blood, phlegm, yellow bile and black bile. If these fluids are in correct proportions, then a person is in a good mood, otherwise he/she is not" (Žagar, 2004, p. 111). Humour is something which causes laughter, it fills us with joy and helps us get into and stay in good mood, be joyful, virtuous and happy. It is a form of entertainment and, at the same 


\section{Acta Educationis Generalis \\ volume 7, 2017, issue 3}

time, a form of human communication, purpose of which is to make people laugh and consequently, to cheer them up.

Investigating the use of humour in nursing is thus very important because nursing is a profession in which a lot of social interaction (and communication) takes place. This paper thus discusses humour within the framework of nursing profession in Slovenia. The specific objective of our study is to explore the attitudes of Slovenian nurses towards humour and their actual use of humour during their interaction with patients.

The remaining part of the paper proceeds as follows. In the theoretical part, we present the main theories of humour and discuss the use of humour in nursing. In the empirical part of our paper, we give and discuss the results of our quantitative study on Slovenian nurses' attitudes towards humour and their use of humour in their work. We also address the relationship between the nurses' education and their sense of humour and their love of work. The final part of the paper draws together the key findings of our research with the implications for the nursing profession education.

\section{Theories of humour}

There are many (albeit less known) theories which deal with the definition, the features and the significance of humour. For the purposes of this contribution, we present only a few classic and a few contemporary theories of humour. Some of the classic theories of humour are as follows:

The social theory of humour defines humour as the means for the establishment of better interactions within a group and for the transmission of cultural mores (Coleman, 1992). The key function of humour is socialization: to acculturate knowledgeable, understanding, compassionate, and empathic new members to the society (Callahan, Clark, \& Kellough, 1992, as cited in Pollak \& Freda, 1997, p. 177). In essence, this theory recognises the purpose of humour and the fact that humour does not only have an impact on the society as a whole, but that humour performs important functions in smaller social groups, too. In a way, it connects the group and controls the behaviour of individual members of a certain group, which strengthens the bonds among individual members of that group. Alternatively, it can cause conflicts among the group members because of different perceptions of humour or because of making fun of other members of the group.

The superiority theory of humour traces its origins to Aristotle and Plato (6th century B.C.). This theory got its more developed version in the 17th century with the works by English philosopher Hobbes, who stated that humour stems from the attainment of superiority over someone else. This theory addresses the relationships between the speaker and the receiver of humour (Raskin, 1985, p. 40). Humour can be used to make a group of people or an individual feel ridiculed and undignified.

According to Kant, the incongruity theory of humour defines laughter as the emotion which appears as a result of a surprise related to a strained expectation of something, and then actually nothing or something completely different from what was expected happens. This theory does not search for the origins of laughter within the motives of people who laugh, but tries to find these reasons in the incongruities in the environment which provoke laughter (Billig, 2005, p. 57). Here, humour appears as the result of the incompatibility between discourses which are socially constructed and learnt (Mills, as cited in Creeber, Miller, \& Tuloch, 2011, p. 63). 


\section{Acta Educationis Generalis \\ volume 7, 2017, issue 3}

The relief theory of humour was advocated by Freud, who stated that humour functions both socially and psychologically as a relief of suppressed emotions and feelings which would otherwise remain hidden. In this way, an individual indirectly challenges cultural norms. Humour can be defined as a physiological mechanism of managing stress, as a model for relieving tensions by releasing excessive (emotional) energy and transforming this energy to the physical one - to laughter. This theory deals only with the feelings and thoughts of the person who interprets humour (Raskin, 1985, p. 40).

Biological, instinctive, developmental theories of humour point out that the proverb "laugher is the best medicine: (in Slovene, "laughter is half one's health") indeed holds true since it has a positive effect both on one's physical health and on one's general wellbeing. That is, "laughter and humour are built in nerve mechanisms and they perform an adaptive function. Laughter establishes homeostasis, maintains normal blood pressure, increases the supply of oxygen into the blood, it massages vital organs, stimulates circulation, relaxes and maintains good mood" (Peštaj, 2006, p. 5).

The incongruity theories describe situations when a person tells a joke that is then associated by another person with another joke, which has different contents, but is related to the first joke in a funny way.

The surprise theory of humour emphasises the psychological aspect of incongruity. The main concepts of this theory are surprise, shock, unexpectedness, suddenness; they deal with humour which can be found in jokes or situations when a person says something completely normal and the other person replies with something funny which the first person did not expect.

Modern theories of humour most frequently stem from the current social and private life. That is why humour changes both as for its form and its contents. Nevertheless, the primary function of humour is still the same - to laugh and to make somebody laugh. Among modern theories of humour, Peštaj (2006, p. 5) highlights the following:

- Developmental theories of humour study the phases in the development of laughter and, thus, most often remain at the descriptive level. The only holistic cognitivedevelopmental theory of humour was developed by P. McGhee, who is a leading theoretician in the field of the study of humour development in children.

- Physical, physiological and neurological theories have encouraged the performance of a large number of experiments. The theory developed by D. Berlyne explains humour with the principles which can be compared with curiosity and researchoriented behaviour.

- Psychoanalytical theories are the theories which are based on the theory of S. Freud. His followers aim to connect his findings with modern physiological theories.

- Socially-oriented theories have encouraged experimenting because they study the changes in experiencing humour in the context of its dependence on social factors, or the function of humour for an individual or a group.

- Cognitive theories study cognitive processes triggered by a humorous stimulus and, related to that, the nature of humorous stimuli.

The core concept of these theories is incongruity. However, the expected (and desired) result of humour is always laughter, which is a natural phenomenon and a mere physiological reaction to humour. Humour is characterized by a series of gestures, the production of sounds and the psychomotor reactions of the person who creates humour and also of the person who experiences it. However, Martin (2007, p. 230) points out 


\section{Acta Educationis Generalis \\ volume 7, 2017, issue 3}

that laughter and humour are not the same thing. Humour can be the result of satisfaction, an expression of sympathy, irony, excitement, comfort and satisfaction, even sarcasm (black humour); it can be an expression of suffering and a means for releasing tensions, dissatisfaction, even sadness. Humour has been researched within social sciences (by sociologists, philosophers, psychologists, etc.) as well as within medical science (psychiatrists, physiotherapists, etc.). All these specialists, including gelotologists (specialists studying laughter), perceived some healing properties of humour. It is medical specialists who predominantly state that laughter is initially triggered in the centre of cerebral cortex where endorphins (i.e. happiness hormones) are released and which results in one's relaxed state, emotional ease and good mood.

\section{Humour and a nurse}

Humour is a form of communication, it is a conversation with oneself and other(s); it can (even) be a lifestyle. In nursing, the "five rights" rule, which stands for the right dose of the right drug in the right form to the right patient at the right time, is universally applied. Kersnič (2002) changed this rule into the " $5 \mathrm{H}$ " rule, i.e. humour in the right dose, humour in the right form, right humour for the right patient, and humour at the right time. Based on the research into humour, Peštaj (2006, p. 6) states that a sense of humour has three meanings: a conformist meaning (i.e. a person with a sense of humour laughs at the similar jokes that we do), a quantitative meaning (i.e. a person laughs a lot and can easily be made to laugh), and a productive meaning (i.e. a person makes other people laugh).

A nurse has a sense of humour when she can make a patient laugh very fast, when she laughs at the same things that are funny to the patient and when she has a treasury of jokes and anecdotes. She creates humour, accepts jokes and does not mind jokes at her own expense. Also, a nurse with a sense of humour is capable of seeing herself and others from a distance. It should be noted that a nurse should know the three core dimensions of humour:

- meta-communication sensitivity (i.e. the ability to recognise humour in a given situation);

- personal affection for humour; and

- emotional admissibility (i.e. free expression of emotions).

If the nurse is aware of the fact that humour is a multidimensional construct, as stated by Peštaj (2006, p. 7), she can produce humour, can be playful and entertaining, can use humour for the attainment of social goals, can recognise humour and see herself as the transmitter of humour, can enjoy humour and can laugh at problems as well as deal with problems with the help of humour. Humour also helps the patient deal with certain problems he/she is confronted with. It helps the patient become integrated into the society and become socialized. It also helps the patient deal with his/her health-related problems more easily. Of course, both the patient and the nurse must first enjoy humour, must get to know it, must master it and, subsequently, use it. Most of all, it is important that they recognise its limits and its quality as well as its purpose. As burnout frequency in the nursing profession is high, "nurses must deal with more or less serious problems, intrapersonal and interpersonal conflicts, stressful situations, and other adverse circumstances" (Leskovic, Vukovič, Leskovar, \& Goriup, 2016, p. 51). Humour can help both the patient and the nurse solve different problems they face in the course of medical 


\section{Acta Educationis Generalis \\ volume 7, 2017, issue 3}

treatment. However, not all nurses have "preferences for humour", which is a more accurate term than "a sense of humour".

Humour can also serve as a defence mechanism as it protects against disjunctive events. During a conflict or in a situation of humiliation or insult, humour eases this social situation and calms down tensions and aggressions. The nurse has to be very careful in her use of humour, she has to be considerate. Her careless use of humour, with the addition of her inappropriate behaviour, can often hurt the patient who comes to her with serious problems. Humour can also distance the patient either from the nurse or from the intention of aggressive behaviour or from any other opposition. The nurse should also not exaggerate in her use of humour, but should use it to alleviate a certain situation. Most of all, the nurse should not use humour just to be funny at any cost.

All theoretical approaches to humour indisputably show that there are many types of humour. Humour also occurs in the relationship between the nurse and the patient; however, they perceive it in different ways and express it in the ways which are inherent to them. It is particularly important to make sure that they do not use jokes which can be misinterpreted, due to their banal contents, by either of them (or both of them). On the one hand, the generally known forms of humour are jokes (plays with language and word plays), body expressions (funny and entertaining body postures, funny faces and gestures, etc.), buffoonery (funny situations with unexpected outcomes), and jokes in a wider sense (they entertain because they show familiar situations from shows, parodies, etc., in a new and usually funny context). On the other hand, there exist less frequently used types of humour - also in the context of nursing. These forms are irony, farce, metaphor, hyperbole, satire and sarcasm. Even though these types of humour are less frequent, we would like to draw attention to them (with the best intentions in mind).

The nurse only rarely uses irony as humour when in contact with the patient. Irony might be used in situations when she wishes to "remind" the patient because the literal meaning of the contents is the opposite of the intended meaning (e.g. "It's so wonderful to be on a sick leave." - but the patient would like to return to work as soon as possible). The nurse uses farces and hyperboles only exceptionally, too. While the former ones are characterized by mental humour, the use of deliberate absurdity or stupidity and stylistically elaborate shows, the latter ones are used as a motivation: to encourage strong emotions or to create a strong impression, but not with the intention that they are to be taken literally. Hyperboles are exaggerations that create an emphasis or an effect. Metaphor, as a type of humour which focuses on a subject which is different on some point of comparison to an unrelated object, is also rarely used by nurses. The Encyclopedia of Health Communication defines metaphor as a figure of speech which is "usually used to denote a particular language device or a characteristic of language; when used in this sense, metaphor is a language property observed in written or spoken language and is properly called "linguistic metaphor" (Thompson, 2014, p. 870). According to the same source, a metaphor can refer to three additional perspectives in health communication, i.e. a cognitive process, a structure inherent in mental entities, and a cultural model (Thompson, 2014).

The nurse tends to use satire more frequently. Satire is an aggressive type of humour because it makes fun of social institutions and social policy (Martin, 2007, p. 13). By using satire, the nurse discloses herself. But humour attracts us more because, as stated by Žagar (2004, p. 111), it is full of jokes and laughter. However, when we are in a bad mood or when we become serious, we reproach satire for its banality, its impropriety or 


\section{Acta Educationis Generalis \\ volume 7, 2017, issue 3}

carelessness - which are, as the author states, the characteristics of satire. Sarcasm as a type of humour is very rare in nursing because it is an aggressive form of humour which focuses on a particular person (Martin, 2007, p. 13). For example, if a nurse said to a drunken patient that he was drunk, he would reply that this was true and would add that she was ugly and old and that he would be sober the next day, but she would still be ugly and old. Irony, which is seldom used by a nurse, is a humorous rhetorical figure which is used for an indirect communication of the message that is the opposite of the literal meaning of the sentence. As stated by Gibbs (1986, p. 3), the language used in an irony is bitter, caustic, and this ironic language is usually directed against an individual. Irony and sarcasm are closely related because ironic statements can also be sarcastic. However, a nurse who is skilled in using humour and is able to make complex linguistic and social conclusions, can use irony not only as a form of criticism but also as giving praise indirectly.

Martin (2007, p. 269) claims that it is important to assess the significance of humour not only as a socially desirable personal characteristic but also as an important part of one's mental health. Apart from arousing strong positive feelings and preventing negative states such as depression and anxiety, humour also acts as an important mechanism for the control of stressful situations in life and is a significant social skill needed to start, maintain and strengthen satisfying interpersonal relationships. This is confirmed by the research on the psychology of humour which has, in recent years, focused on the relationship between humour and different aspects of mental health. That is, one of the components of humour is a positive emotion of joy which emerges when the nurse and the patient joke and laugh. They thus feel more relaxed and happy and less depressed, restless, irritable and tense. This leads us to the conclusion that humour enhances positive mood and prevents negative feelings.

\section{Nurses need to be educated for ergonomics in the workplace}

An educational package of common ergonomic training as well as behavioural training and training for humour was implemented in nursing education (Balantič \& Fležar, 2014, pp. 2-4). Teaching methods were also applied with the aim to increase students' awareness of the importance of total work environment for the prevention of back injuries. The experimental group was, on the whole, more pleased with their education than the control group. The experimental group assessed their ability to analyse the work environment better than the control group did. Observations in some practical workrelated tasks showed that students from the experimental group worked in physically more favourable positions with less strain on the body (Olendorf \& Drury, 2001, pp. 1341-1367).

Ergonomics is especially important in the caregiving setting, where many patients rely on staff members for mobility (Choobineh, Movahed, Tabatabaie, \& Kumashiro, 2010, pp. 74-84). Medical professionals suffer the highest work-related injury rates of all employees. To reduce injuries, caregiving institutions provide special equipment to assist employees with patient care. While these tools help, employees ultimately create a safe work environment, as reported in the blog on ergonomics in nursing (http://online.adu.edu/blog/bsn/articles/ergonomics-in-nursing/).

According to the Bureau of Labor Statistics (BLS), medical personnel suffer the most injuries among all US workers - with every 68 hospital workers, 107 nurses and 174 EMTs per 100,000 fulltime employees injuring themselves on the job, primarily while 


\section{Acta Educationis Generalis \\ volume 7, 2017, issue 3}

maneuvering patients (Balantič \& Fležar, 2004, pp. 2-4). Healthcare institutions estimate $\$ 20$ billion in losses due to employee back injuries alone. As a result, the healthcare industry recognizes manual maneuvering as a risk for employees and patients. Ergonomics helps reduce workplace injuries due to physical activity. When an employee's workload is too demanding, this risk increases. Ergonomic practices and equipment decrease the impact work places on the body, preventing injuries before they occur.

Unknown physical stressors create workplace hazards. Many patients rely on healthcare workers for physically demanding mobility services. Each service a medical professional performs can potentially result in harm to the worker and patient, which increase healthcare costs due to worker absences, turnover and shortages. Caregiving facilities that implement ergonomic practices experience fewer employee injuries. Depending on the setting, caregiving facilities may provide ergonomic equipment to assist employees such as sliding boards, lateral transfer aids, transfer chairs, gait belts, full body lifts, standing and repositioning lifts, bedding modifications, geriatric chairs. The occupational safety and health administration (OSHA) demands from employers to maintain work environments that are safe for employees and patrons (SPHM, 2016). In caregiving settings, this includes providing equipment to minimize or eliminate manual patient lifting.

OSHA regulations require employers to document policies that can prevent work-related injuries. Healthcare administrators must then continually educate and monitor medical personnel regarding policies such as proper patient lifting and transfer methods. OSHA also requires caregiving facilities to implement procedures to report the first signs of work-related physical duress (Linton \& van Tulder, 2001, pp. 778-787).

Workplace analysis is a tool that healthcare administrators use to identify and prevent current and future safety hazards by evaluating task duration, repetition, environment and other factors to determine if work responsibilities present injury risks to employees (Rainville, Hartigan, Martinez, Limke, Jouve, \& Finno, 2004, pp. 106-115). To accomplish this, healthcare administrators observe, communicate with and poll current staff members. Administrators also review past injuries and worker compensation reports to identify chronic safety hazards (Yip, 2004, pp. 430-440).

Healthcare administrators update and teach safety procedures regularly based on their ongoing evaluations. Administrators make sure that employees receive and understand updates expeditiously and encourage feedback from staff members concerning safety issues. Basic safety policies outline leading back injury causes, risks and symptoms as well as other work-related injury hazards (Park \& Shin, 2016, pp. 2761-2766). Administrators teach medical personnel how to recognize and report injuries, and as a preventative measure, encourage employees to maintain physical fitness. Ergonomic training typically includes lifting education. Administrators remind nurses not to lift patients unless they have firm footing and to keep patients close to ease lifting. Additionally, nurses should never lift patients alone, especially if a patient has fallen. Nurses should ask peers to help lift patients or use mechanical assistance and limit how many times per day they complete the task (Santaguida, 2003).

Evaluation and procedures do not make a workplace safe; it is the inclination of workers to follow safety guidelines (Choobineh, Movahed, Tabatabaie, \& Kumashiro, 2010, p. 74-84). Therefore, it is important that administrators carefully plan how to train employees, especially if it is a new concept. New initiatives must begin with open 


\section{Acta Educationis Generalis \\ volume 7, 2017, issue 3}

support from the top management. Before institutions install new equipment in the workplace, healthcare administrators must educate stakeholders on what purpose the device serves and how to use it, because employees that participate in the change process beforehand are more likely to support the agenda (Vural \& Sutsunbuloglu, 2016, pp. 174-178). Once the new equipment is in place, administrators should measure safety improvements and reward employees for adopting the new technology. Administrators must also determine how to gather measurable safety data from the new devices.

Healthcare administrators make sure that their organizations comply with OSHA standards. These regulations, based on ergonomic principles, greatly reduce employee injuries. In the caregiving field, mechanical assistance is a key component of these principles, which also serve to increase patient safety and comfort. When accidents do occur, administrators are responsible for accurately identifying and managing injured staff members (Yip, 2004, pp. 430-440).

\section{Barriers for awareness of humour needed in education for nurses}

As noted in several reports, the level of awareness of humour and ergonomic topics is low in the communities most affected by it. Nurses were unaware of the consequences of untreated topics. They had poor knowledge on the connection between humour, ergonomic topics and education for them as they had not yet been coping with these issues. There are some possible explanations for this phenomenon. Curriculum for the education of nurses is (mostly) dealing with other serious health priorities. So, nurses were in conflict over the possible inference with other priority health concerns. In addition, access to health care and healthcare resources are, almost by definition, restricted and under-resourced in these areas. Together with these disparities there are the gaps perpetuated in the training of medical personnel.

Teaching in some countries tends to mimic that, in developed countries, it is unlikely to take into account differences in public, private, and primary healthcare strategies. It is crucial that medical education in developing countries is defined by the needs and services required by the majority of the people. We have recently seen, though, that the importance of integrated primary healthcare services and management of humour and ergonomic topics is gaining momentum and the artificial dichotomy between diseases is slowly receding in favour of a combined approach that will benefit all conditions (Zühlke \& Engel, 2013, p. 236). Although nurses report attempts to educate patients on the causes of the importance of humour for adhering to secondary prophylaxis, patients still have very low levels of understanding humour regarding the specifics means of it. Language also plays a very important role. Therefore, nurses need to recognize the importance of performing these explanations in the local language observing cultural particularities and levels of literacy and understanding. Even complex concepts of using humour can be clearly understood, given appropriate communication strategies. Awareness of the patients' needs and cultural background should take precedence in the conversation around expectations of adherence and follow-up. It is known that nurses' explanations and the level of patients' understanding significantly affect treatment adherence, treatment outcome, and patients' satisfaction. Therefore, nurses need to be critically aware of these issues when communicating with patients in humour, select humour contents that are appropriate to the patient's level of understanding, and employ a systematic approach utilizing a variety of mechanisms (e.g. printed material, displays, videos, and discussions) to educate and improve awareness and stress motivating 


\section{Acta Educationis Generalis \\ volume 7, 2017, issue 3}

principles, cultural relevance, and feasibility. The importance of education for using humour in the subtle way is emphasized, as well as utilizing lessons learned from other.

The identification of key priorities a priori and setting realistic and focused goals are crucial for the success of using humour. Education for using humour in health care must be directed at all levels, and multiple channels should be used to disseminate information. Clinical care should be also addressed with the incorporation of clinical care coordination, standardized delivery methods, and case-finding activities. The primary objective of this educational program should create a simple, modular, but comprehensive model for using humour when dealing with patients and other nurses, as well. Strategic design is the key element for such successful educational health program including humour topics. To improve it in a lasting and significant way, it is critical to initiate cultural promotion strategies that are collaboratively designed, locally adapted and implemented on multiple levels and comprehensively understood. The overarching component of an effective educational health communication program, which incorporates humour topics, however, remains a powerful, well-articulated, long-term vision. This needs to reflect the core values and beliefs of the nursing team and the shared scenario for the future. It should stimulate teamwork and inspire a concerted, committed effort in creating constructive conversations around the core messages.

\section{Some Proposals}

As the most significant developments affecting nursing education in Slovenia regarding the use of humour, the proposals for restructuring the syllabus of health care education should have particular regard to:

- contemporary and anticipated needs of humour in health care;

- the outcomes-based approach to humour for practice;

- a sound assessment humour practice and its integration in theory;

- the nature of and standards for the training of nursing;

- positioning humour topics in relation to possible inter-syllabus subjects approaches where appropriate;

- overcoming the lack of opportunities between nurse's entry qualification for using humour and its need which is required in practice;

- stating standards of using humour topics;

- a growing emphasis on prevention, yet a great demand for therapeutic use of humour; and

- supporting nurses in enhancing the quality of witty contents.

We suggest that the educational topics for nurses might apply the contents of humour in their education to their everyday practice, contemporary syllabus does contain Sociology of Health and Illness subject, for example, which has its roots in the discipline of Sociology thus presenting an attempt to make sense of using humour. We nevertheless emphasise that the syllabus in general should pay attention to the control over the events in nursing and the learning environment, as it is preferable to consider the contribution of this subject as helping nursing students and nurses to use and interpret humour situations rather than just avoid or except them, and thus influence events occurring in the learning or in professional environment. As nurses hold a "world-view" about their professional work, the literature of Sociology of Health and Illness can help them reevaluate and re-interpret the topics of humour and hence influence their future practice. Nurses' critical understanding of using humour implies that, during their education, 


\section{Acta Educationis Generalis \\ volume 7, 2017, issue 3}

future nurses should adopt a critical approach to a range of sociological theories, identify inconsistencies and contradictions between them, and assess the quality of evidence supporting each theory and practical application in their education. Learning theories have attempted to provide explanations about learning that apply to nurses in general; however, in health care system, there are no nurses in general, because every nurse is individual and unique. At best, general approaches can provide insight into some of the phenomena that are likely to be associated with learning to use humour in their practice, but nurses as individuals should (and will) differ in the degree of using humour to which such phenomena manifest themselves.

As claimed above, the current Slovenian educational system in nursing has a number of weaknesses as for humour topics and using them in practice, it fosters the feeling of dependence and assigns them a passive role in learning and it may reduce their motivation as well as cause resentment or hostility about them. On one hand, the subject Sociology of Health and Illness does rely on the students' previous knowledge about using humour as well as on the key role of the facilitator very much. There should be a synergy attempt to capitalize on the best features of both Sociology of Health and Illness and nursing syllabus for professional training by making use of expert knowledge about using humour and in the same time, encouraging active involvement of nurses and students to learn from one another through structured interactions. Observational learning is potentially a powerful tool for nurses in practice and for students because of a wide range of applications. Therefore, we recommend problem-based learning of using humour as a strategy in teaching nursing and define it as learning that results from the nurse's process of working towards understanding the proper use of humour when dealing with patients and their relatives. In problem based learning, which (usually) starts with the problem how to use humour in dealing with patients, students and nurses have to find a proper resolution, be under intrinsic or extrinsic conditions. The adoption of humour can take some time to come to fruition as it depends on the establishment between all persons involved, their feelings and values, and the aspects considered crucial in the humanistic approach which focuses on the relationship between nurses and patients, each considered to be individuals.

\section{Empirical part}

Based on the theoretical foundations concerning humour and previous research into humour, and taking into account humour in nursing as the focus of our research, the study presented in this paper sets out to answer the following research questions:

Research question 1: What is the relationship between Slovenian nurses' level of education and their sense of humour and love of work?

Research question 2: What is the frequency of the use of humour (verbal jokes) by Slovenian nurses?

Research question 3: What is the frequency of the use of irony as type of humour by Slovenian nurses?

Research question 4: What is the attitude of Slovenian nurses towards the need for humour at work and what is their perception of the presence of humour in nursing? 


\section{Acta Educationis Generalis \\ volume 7, 2017, issue 3}

\subsection{Study participants and study design}

The aim of our research was to contribute to a better understanding of the significance of humour in nursing both for the employees and for the patients. In the empirical part, we focused on the attitude of nurses towards the use of non-standard forms of humour in their work. We adopted a quantitative research design and our study was conducted in the form of a survey. The data were gathered via a questionnaire, which was administered to 350 nurses; a total of 279 questionnaries returned were suitable for further analysis. We applied the frequency distribution method (f, f\%), the $\chi^{2}$ test to compare the differences and Spearman rank correlation test (rho) to measure the degree of association between two ordinal variables. All analyses were carried out using SPSS. For the purpose of this paper, we report and discuss only a part of all empirical data gathered within our survey. The results of our study are presented and discussed below.

\subsubsection{Research question 1}

The first research question addressed the relationship between Slovenian nurses' level of education and their sense of humour and love of work. The responses by survey respondents are reported in Table 1 and Table 2 below.

Table 1

Survey participants' level of education

\begin{tabular}{llcc}
\hline \multirow{3}{*}{ Valid responses } & Level of education & Frequency & Percent \\
\cline { 2 - 3 } & Upper secondary & 46 & 16.5 \\
& Higher vocational college & 69 & 24.7 \\
& University (undergraduate) & 73 & 26.2 \\
& University (graduate) & 91 & 32.6 \\
& TOTAL & 279 & 100.0 \\
\hline
\end{tabular}

The acquired empirical data show a realistic picture of the education structure of nurses in Slovenian nursing.

Table 2

Spearman rank correlation coefficient - education, sense of humour and love of work

Spearman coefficient (rho)

* Nurses' level of education $0.537 * *$ $\underline{\text { Sense of humour }}$

Love of work

\subsubsection{Research question 2}

The second research question focused on the frequency of the use of humour (verbal jokes) by Slovenian nurses (see Table 3 for the results). 


\section{Acta Educationis Generalis \\ volume 7, 2017, issue 3}

Table 3

Frequency of the use of verbal humour (verbal jokes)

\begin{tabular}{ccc}
\cline { 1 - 2 } Valid responses & 37 & Percentage of responses \\
\cline { 2 - 3 } Never & 23 & 13.2 \\
Once & 89 & 8.3 \\
More than once & 35 & 32.2 \\
Often & 95 & 12.7 \\
Very often & 279 & 34.4 \\
TOTAL & 100.0 \\
\hline
\end{tabular}

As Table 3 shows, $13.2 \%$ of study participants have not (yet) used verbal humour (verbal jokes) and $8.3 \%$ have used it only once. Verbal humour was used more than once by nurses taking part in our survey $(32.2 \%)$ and similar results were observed with nurses who stated that they have used verbal jokes often 12.7\%). The highest percentage of nurses used verbal humour very often $(34.4 \%)$. The mean value for this statement was 3.75 with standard deviation of 1.17 .

\subsubsection{Research question 3}

The third research question investigated the use of irony as a type of humour by Slovenian nurses. We give the frequency and the corresponding percentages of the use of irony by Slovenian nurses in Table 4 below.

Table 4

Use of irony as a type of humour

\begin{tabular}{ccc}
\hline Valid responses & Number of responses & Percentage of responses \\
\cline { 2 - 3 } Never & 150 & 53.7 \\
Once & 34 & 12.3 \\
More than once & 21 & 7.5 \\
Often & 64 & 22.9 \\
Very often & 10 & 3.6 \\
TOTAL & 279 & 100.0 \\
\hline
\end{tabular}

So many negative responses are not surprising, and this confirms the fact that nurses have never accepted irony as a form of communication let alone as a type of humour. That is, $53.7 \%$ of all respondents in our sample stated that they had never used irony as a type of humour. $12.3 \%$ of the respondents had experienced irony only once, whereas $7.5 \%$ of them experienced irony as a type of humour more than once. Only few respondents stated that they used irony often $(22.9 \%)$ or very often $(3.6 \%)$. The mean value for this statement was 1.57 with standard deviation of 1.07 .

\subsubsection{Research question 4}

The fourth research question looked at the attitude of Slovenian nurses towards the actual need for humour at work as well as their perception of the presence of humour in 


\section{Acta Educationis Generalis \\ volume 7, 2017, issue 3}

nursing. As FOR the need for humour, we were interested in establishing whether nurses need humour in interaction with patients in the course of their work. The results are shown in Figure 1.

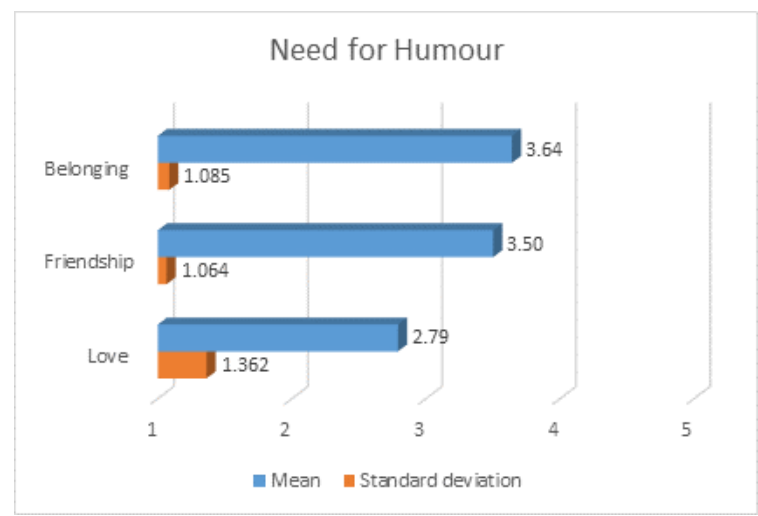

Figure 1. Need for humour by Slovenian nurses.

Regarding the need for humour during their work with patients, nurses participating in this survey showed the highest degree of agreement with the statement "belonging to the nursing profession" with 3.64. For this statement, standard deviation was 1.085 , which means that the respondents' answers were relatively uniform. The second need for humour (in terms of the level of agreement) was "friendship" with the mean value of 3.5 and standard deviation of 1.064. The lowest degree of agreement regarding the need for humour at work was established for the statement "love of work". Here, the mean value was 2.79 and standard deviation was 1.362 , which signifies that the responses given by the nurses were not very uniform.

In Figure 2, we show how Slovenian nurses assess the presence of humour in their professional context.

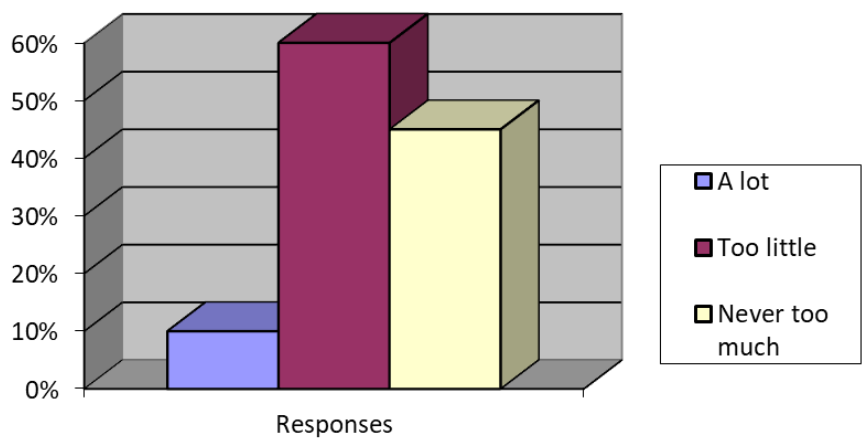

Figure 2. Assessment of the presence of humour in nursing. 


\section{Acta Educationis Generalis \\ volume 7, 2017, issue 3}

The vast majority of nurses taking part in our survey indicated that there is too little humour in nursing or that there is never too much humour in nursing. Only a small percentage of nurses stated that there is a lot of humour in nursing.

Table 5 below shows the attitude of Slovenian nurses concerning the inclusion of humorous contents.

Table 5

Attitude of respondents towards the inclusion of humorous contents.

$\underline{\text { Statement }} \quad \underline{N} \quad \underline{\text { Mean }} \frac{\underline{\text { Standard }}}{\underline{\text { deviation }}} \quad \underline{t} \quad \underline{g} \quad \underline{p}$

Humorous contents should be

included in the nurse's work

with patients.

$\begin{array}{llllll}279 & 3.31 & 0.741 & 22.617 & 425 & <0.001\end{array}$

The average value regarding the agreement of the survey participants with the statement that humorous contents should be included in the nurse's work with patients was 3.31. This score was above the middle value of the four-point scale, which is 2.5 . The t-test for this statement was statistically significant $(\mathrm{p}<0.001)$.

To summarize our findings presented in this paper, the following observations can be made. This study has shown that Slovenian nurses are prone to the use of humour in their work. Moreover, they welcome humour as an integral part of their work with patients. This is supported by their belief that humour also enhances their sense of belonging to the nursing profession. Slovenian nurses, as was determined by our research, acknowledge the presence of humour and the important role it plays within the context of their work. Our study has also demonstrated a clear positive link between the nurses' level of education, their sense of humour, and love of work. Despite the fact that this paper presents only a small segment of our research into humour in nursing, the findings reported here provide a valuable insight into this topic.

\section{Conclusion}

This study provides initial support for the need of the topics of humour as a therapeutic strategy in nurse's education. We are aware of several limitations, some of them are inherent in the investigation caused by the lack in the education of nurses. As nurses tend to see humour as healing, humour should be integrated into the educational programme that teaches health care promotion. Without the presence of sympathy and affection, nurses and patients could not define humour as emotionally supportive and caring.

The following conclusions can be also drawn from the present study. Nurses used humour to care for patients and to attain therapeutic goals. Humour elicited positive responses providing compassion and increased the patient's ability to perceive incongruity as amusing. Nurses used humour therapeutically as they perceived humour in this way, as they were conscious that humour must be perceived as kind. Nurses themselves are one of the factors that have to be considered when researching the use of humour in their work. In their interaction with patients, nurses are not only professionals, 


\section{Acta Educationis Generalis \\ volume 7, 2017, issue 3}

but they also have a big social power. The needed intimacy is achieved when nurses and patients are able to take on each other's roles. Nurses have to develop their own type of humour, they have to learn how to plan it and how to recognise the need for its use on the one hand, while on the other hand, they have to be aware of the traps and dangers of using humour and how to avoid them. Nurses also strive to moderate their humour in serious situations and they try to find the balance between the needed silliness and sternness. Before using humour, nurses usually use several non-humour therapeutic communication methods, such as careful listening, touch, eye contact or appropriate verbal remarks, as they are aware of their lack of needed knowledge, as they are not trained to use humour in contacts with patients. A nurse can play with language and thus create puns and other types of verbal humour and look for double meanings in words and incongruities in everyday situations with patients and their relatives, as well. A variety of resources are available, including humorous health care journals, humour organizations, and catalogues. Many nurses believe that they need the skills of a professional comic, even if many people believe nursing is a serious business and humour will make it frivolous and undignified. Improving a nurse's sense of humour requires her active participation.

Nurses' work and tasks are related to their work with people. That is why it is important to be aware that in order to manage changes in nursing efficiently, it is necessary to focus on a person, to use human resources reasonably and efficiently, to train, motivate and develop nursing staff, to introduce modern forms of management and to aim for an efficient internal communication.

As an old saying goes, "laughter is the best medicine", and this still holds true today. It has been proven that laughter increases the supply of oxygen and the release of happiness hormones, relieves stress, reduces pain and lowers blood pressure. If laughter is the elixir of life, humour can be a medication; it can protect the body and the soul in the times of crisis. The physician and comedian Eckart von Hirschhausen (2011) is convinced that "humour helps heal". He promotes the importance of therapeutic laughter - in medicine, in the world of work, in public. Humour introduces trust into a relationship and it provides a feeling of connectedness. It is, and it can be a facilitator of social interaction. Humour is a creative way of overcoming life obstacles in general. One only needs to be aware of this and needs to use it (sensibly).

\section{References}

Balantič, Z., \& Fležar, M. (2004). Lung function deficit - how to explain it to a patient? In G. S. Firestein (Ed.), 3rd International conference on occupational risk prevention (pp. 2-4). Barcelona, Spain: Escola Tecnica Superior d'Enginyeria Industrial.

Billig, M. (2005). Laughter and ridicule: Towards a social critique of humour. London, Thousand Oaks, New Delhi: Sage.

Callahan, J., Clark, L., \& Kellough, R. (1992). Teaching in the middle and secondary schools. New York: Macmillan.

Centers for Disease Control and Prevention. Safe Patient Handling and Movement $(S P H M)$. Centers for Disease Control and Prevention. Retrieved from https://www.cdc.gov/niosh/topics/safepatient/ 


\section{Acta Educationis Generalis \\ volume 7, 2017, issue 3}

Choobineh, A., Movahed, M., Tabatabaie, S. H., \& Kumashiro, M. (2010). Perceived demands and musculoskeletal disorders in operating room nurses of Shiraz city hospitals. Industrial Health, 48(1), 74-84.

Coleman, J. J. (1992). All Seriousness aside: The laughing - learning connections. International Journal of Instructional Media, 19(3), 269-274.

Creeber, G., Miller, T., \& Tuloch, J. (2011). The Television Genre Book. London: British film institute.

Ergonomics in Nursing [Web log post]. (n.d.). Retrieved from http://online.adu.edu/blog/bsn/articles/ergonomics-in-nursing/

Gibbs, R. W. (1986). On the psycholinguistics of sarcasm. Journal of Experimental Psychology: General, 15(1), 3-15.

Kersnič P. (2002). Zdravje in humor s smehom. Medicinski sestri za vsakdanjo rabo. In K. Urbančič, D. Klemenc (Eds.), Spoznajmo komplementarno in naravno zdravilstvo tudi v zdravstveni negi: zbornik člankov s strokovnega srečanja - 1 . simpozija Društva medicinskih sester in zdravstvenih tehnikov Ljubljana, Kranjska gora, 4. decembra 2002 (pp. 243-249). Ljubljana, Slovenia: Društvo medicinskih sester in zdravstvenih tehnikov.

Leskovic, L., Vukovič, G., Leskovar, R., \& Goriup, J. (2016). Some Aspects of Burnout in Nursing Homes. Acta Technologica Dubnicae, 6(2), 47-62. doi: 10.1515/atd2016-0011

Linton, S.J., \& van Tulder, M.W. (2001). Preventive interventions for back and neck pain: What is the evidence? SPINE, 26(7), 778-787.

Martin, R. A. (2007). The psychology of humour: An integrative approach. Amsterdam: Elsevier Academic Press.

Occupational Safety and Health Administration. Hospital eTool: Healthcare Wide Hazards - Ergonomics. Retrieved from https://www.osha.gov/SLTC/etools/ hospital/hazards/ergo/ergo.html

Olendorf, M. R., \& Drury, C. G. (2001). Postural discomfort and perceived exertion in standardized box-holding postures. Ergonomics, 44(15), 1341-1367.

Park, S., \& Shin, S.Y. (2016). Manual therapy of shoulder musculoskeletal diseases when arms are lifted while spread straight. Information, 19(7), 2761-2766.

Peštaj, M. (2006). Kako otroci prepoznavajo na humor in se nanj odzivajo. Panika: širimo psihološka obzorja, 10(3), 5-27.

Pollak, J. P., \& Freda, P. D. (1997). Humor, learning, and socialization in middle level classrooms. The Clearing House, 70(4), 176-178. Retrieved from http://www.jstor.org.ezproxy.lib.ukm.si/stable/30189278

Rainville, J., Hartigan, C., Martinez, E., Limke, J., Jouve, C., \& Finno, M. (2004). Exercise as a treatment for chronic low back pain, The Spine Journal, 4(1), 106115.

Raskin, V. (1985). Semantic mechanisms of humor. Dordrecht: D. Reidel.

Santaguida, S. (2003). Intervention strategies to reduce musculoskeletal injuries associated with handling patients: a systematic review, Occupational Environmental Medicine, 60(9), E6.

Thompson, T. L. (2014). Encyclopedia of health communication. Thousand Oaks, CA: SAGE Publications, Inc. 


\section{Acta Educationis Generalis \\ volume 7, 2017, issue 3}

von Hirschhausen, E. (2011). Humor hilft heilen. In K. Münstedt (Ed.), Komplementäre und alternative Krebstherapien (pp. 197-208). Landsberg/Lech: ecomed-Storck $\mathrm{GmbH}$.

Vural, F., \& Sutsunbuloglu, E. (2016). Ergonomics: an important factor in the operating room. Journal of Perioperative Practice, 26(7-8), 174-178

Yip, V. Y. B. (2004). New low back pain in nurses: work activities, work stress and sedentary lifestyle. Journal of Advanced Nursing. 46(4), 430-440.

Zühlke, L. J., \& Engel, M. E. (2013). The importance of awareness and education in prevention and control of RHD. Global heart, 8(3), 235-239.

Žagar, F. (2004). Humor o šoli in šola o humorju. Maribor: Obzorja. 